\title{
The Location of Highly Repetitious DNA in the Somatic Chromosomes of Drosophila melanogaster
}

\author{
William J. Perreault ${ }^{1}$, Karen P. Adkisson ${ }^{2}$, S. R. Cobel-Geard, and Helen Gay \\ Division of Biological Sciences, University of Michigan, Ann Arbor, Michigan 48109 U.S.A. \\ present addresses: ${ }^{1}$ Biology Department, Lawrence University, Appleton, Wisconsin 54911 U.S.A.; \\ ${ }^{2}$ Biology Department, Roanoke College, Salem, Virginia 29153 U.S.A.
}

\begin{abstract}
In situ hybridization of Drosophila melanogaster somatic chromosomes has been used to demonstrate the near exact correspondence between the location of highly repetitious DNA and classically defined constitutive heterochromatin. The $\mathrm{Y}$ chromosome, in particular, is heavily labeled even by cRNA transcribed from female (XX) DNA templates (i.e., DNA from female Drosophila with $2 \mathrm{Xs}$ and 2 sets of autosomes). This observation confirms earlier reports that the Y chromosome contains repeated DNA sequences that are shared by other chromosomes. In grain counting experiments the $\mathrm{Y}$ chromosome shows significantly heavier label than any other chromosome when hybridized with cRNA from XY DNA templates (i.e., DNA from male Drosophila with $1 \mathrm{X}$ and $1 \mathrm{Y}$ plus 2 sets of autosomes). However, the preferential labeling of the $\mathrm{Y}$ is abolished if the cRNA is derived from XX DNA. We interpret these results as indicating the presence of a class of $\mathrm{Y}$ chromosome specific repeated DNA in D. melanogaster. The relative inefficiency of the $X$ chromosome in binding cRNA from XY and $X Y Y$ DNA templates, coupled with its ability to bind $X X$ derived cRNA, may also indicate the presence of an $\mathrm{X}$ chromosome specific repeated DNA.
\end{abstract}

\section{Introduction}

The field of cytogenetics has enjoyed some remarkable advances in recent years. Questions about chromosome structure and function which have remained unanswered during more than a generation of investigation, now are being resolved by the application of such innovations as molecular hybridization and new staining techniques. No better example can be given than to contrast the prevailing opinions about the chemical nature of heterochromatin ten years ago, and now. A decade ago and earlier, the concept of a distinctive chemical identity for heterochromatin was not appealing to most investigators. The view that heterochromatin is simply some form of permanently "out of phase" chromo- 
some material seemed a more plausible alternative. In the minds of some, however, there was a conviction that in a very fundamental way heterochromatin must be chemically distinct from euchromatin. The question of what kind of a difference to look for, and how to go about proving that there is a difference, loomed large in their minds. One day, they believed, a method would be found and heterochromatin would turn out to be, after all, a very interesting substance. Such a person was the late Dr. Berwind P. Kaufmann, to whose memory we respectfully dedicate this paper.

In a relatively brief period it has become clear that repetitious DNA and/or satellite DNA is an invariate and perhaps diagnostic component of the constitutive heterochromatin of many organisms. This concept originated with the discovery by Yasmineh and Yunis (1969) that satellite DNA is associated with centromeric constitutive heterochromatin in the mouse. With the development of in situ hybridization methods (Pardue and Gall, 1969), interest quickly shifted to the archetypal organism for studies of constitutive heterochromatin, Drosophila melanogaster. Several investigators used in situ hybridization to demonstrate that the chromocenter of $D$. melanogaster polytene nuclei is the locus of highly repetitious DNA (Rae, 1970; Jones and Robertson, 1970; Botchan et al., 1971; Gall et al., 1971; reviewed by Laird, 1973). The distribution of repeated DNA sequences has also been roughly correlated with the major blocks of heterochromatin in somatic cells (Gall et al., 1971). Other experimental approaches such as analytical centrifugation (Blumenfeld and Forrest, 1971) and filter hybridization (Perreault et al., 1973) have led to the, realization that the heterochromatic $\mathrm{Y}$ chromosome must be relatively rich in repeated DNA.

While the above experiments firmly establish a connection between repeated DNA and constitutive heterochromatin, the mere existence of highly repetitious DNA in heterochromatin raises a number of vital questions. We here concentrate on questions which probably must be answered before we can understand the function of highly repetitious DNA. To what extent are repeated DNA sequences of one chromosome shared by other chromosomes? It has been shown (Perreault et al., 1973; Sederoff et al., 1975) that Y chromosome DNA is capable of hybridizing with DNA derived from XX flies or cell lines. Also, recent studies by Peacock et al. (1977) have shown that each of five satellite DNAs are found on all of the chromosomes of the D. melanogaster complement. If this sharing of repeated DNA sequences between chromosomes exists, then what of the opposite case: are some repeated DNA sequences strictly chromosome specific? In addition, does the $\mathrm{Y}$ chromosome contain more repeated DNA than the others? Although experiments cited above have been interpreted as indicating this to be true, it has never been directly demonstrated. Indeed, the Y chromosomes of other Drosophila species have been shown to be deficient in highly repetitious DNA (Gall et al., 1971; Hennig et al., 1973).

In this study we address the above questions by examining the pattern of label distribution on $D$. melanogaster somatic chromosomes after in situ hybridization with cRNA derived from repeated DNA. We take advantage of the ability to select from among several karyotypes of this species (XX, XY, and $X Y Y$ ) to demonstrate that each chromosome has its own characteristic allotment of repeated DNA. We confirm other reports that the Y chromosome 
shares some DNA sequences with other chromosomes. In addition, we have evidence that is compatible with the idea that both the $\mathrm{X}$ and the $\mathrm{Y}$ chromosome may contain a chromosome specific repeated DNA.

\section{Materials and Methods}

The Drosophila stocks used in this study were: (1) wild type (Swedish-b) from which we obtained $\mathrm{XX}$ females and XY males; (2) $s c^{8}$. Y y ac v/y ac v, from which XYY males were obtained,

Cytological squash preparations were made from cerebral ganglia of third instar larvae. The sex of the animals was noted prior to dissection. Slides suitable for grain counts were made from neuroblast cell preparations according to the technique described by Cobel-Geard and Gay (1978). To facilitate the identification of particular chromosomes, photographs were taken of wellspread metaphase stages prior to the hybridization steps. The same cells were photographed again after hybridization and development of the autoradiographs; a correspondence of silver grains and specific chromosomal regions was made.

DNA was isolated from ten gram batches of adult $D$. melanogaster by a method which is similar to that of Laird and McCarthy (1968). Our procedure differs from theirs in that we deproteinize with chloroform-isoamyl alcohol $(24: 1 \mathrm{v} / \mathrm{v})$. The DNA was dissolved in $0.12 \mathrm{M}$ phosphate buffer, $\mathrm{pH} 6.8$, sonicated, and heat denatured. DNA fragment size of approximately 400 nucleotide pairs was confirmed by electron microseopy and sedimentation velocity.

To recover the repetitious portion of the DNA, heat denatured DNA fragments were allowed to reassociate for specified periods at $60^{\circ} \mathrm{C}$. The renatured DNA was separated from the remaining single stranded DNA by chromatography on hydroxylapatite (Britten and Kohne, 1968), dialyzed for $24 \mathrm{~h}$ against $7 \times 10^{3}$ volumes of Tris buffer (Jones and Robertson, 1970), and frozen at $-20^{\circ} \mathrm{C}$ until used as template. Originally, to insure that all components of the rapidly reassociating DNA would be available for transcription into cRNA, we reassociated to equivalent $\mathrm{C}_{0} t$ values of 10 or 15. After examining numerous experiments using various $C_{0}$ t values $(10-15$ and $<0.1)$, we believe that the significant labeling of the somatic chromosomes is due to their reaction with cRNA derived only from the most highly repetitious portion of the genome.

cRNA was prepared by the method outlined in Jones and Robertson (1970). In our system all four nucleoside triphosphates were tritium labeled (New England Nuclear Corp.) and the RNA polymerase was obtained from Mann Biochemicals Inc.

In situ hybridization and elimination of unbound CRNA by pancreatic ribonuclease were carried out by the method of Pardue et al. (1970) with one variation -in our experiments chromosomal DNA was often denatured in a solution of $0.2 \mathrm{~N} \mathrm{HCl}$ at $37^{\circ} \mathrm{C}$ for $30 \mathrm{~min}$. Following Pardue et al. (1970), other preparations were treated by alkali denaturation $(0.07 \mathrm{~N} \mathrm{NaOH}$ for $2 \mathrm{~min}$ ). However, no difference in acid or alkali treated cells was detected in this study. After the hybridization and washing steps, the slides were covered with a solution of Kodak NTB-2 and stored dessicated at $4^{\circ} \mathrm{C}$ for $20-50$ days. Autoradiographs were developed in Kodak D-19 for 2 min at $18-20^{\circ} \mathrm{C}$, rinsed in $2 \%$ acetic acid, and fixed in Kodak rapid fixer for $3 \mathrm{~min}$.

\section{Results}

\section{A. General Labeling Pattern}

Figure 1 typifies the labeling pattern obtained when $\mathrm{XX}$ repeated DNA (i.e., from females with 2 Xs plus 2 sets of autosomes) is used as template for cRNA synthesis, and the somatic chromosomes are derived from male larvae. In every cell with recognizable chromosomes the same pattern is found: (1) the Y chromosome has silver grains over its entire length; (2) the $\mathrm{X}$ chromosome shows silver grains over the proximal heterochromatic (centromeric) region; (3) the 

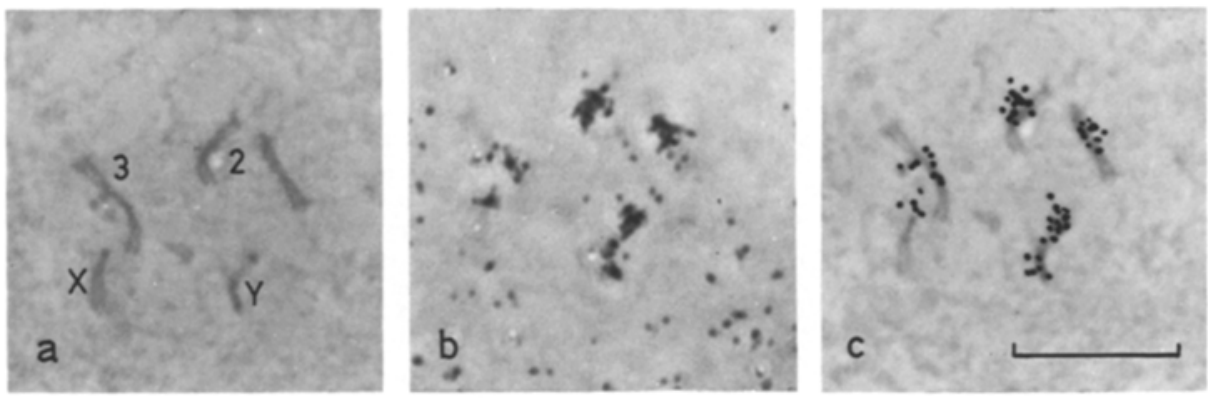

Fig. 1a-c. In situ hybridization of cRNA of $X X\left(C_{0} t 10\right)$ DNA to somatic chromosomes of the Sw-b stock of $D$. melanogaster. a Chromosomes in phase contrast before hybridization. b Autoradiograph of the chromosomes in $\mathbf{a}$. $\mathbf{c}$ Tracing of the silver grains in $\mathbf{b}$ superimposed on the chromosomes of a. Note that the $\mathrm{Y}$ chromosome is completely labeled, as are the fourth chromosome, the proximal heterochromatin of $\mathrm{X}$ and the centromeric regions of 2 and 3. The centromeric region of 2 is more strongly labeled than that of 3
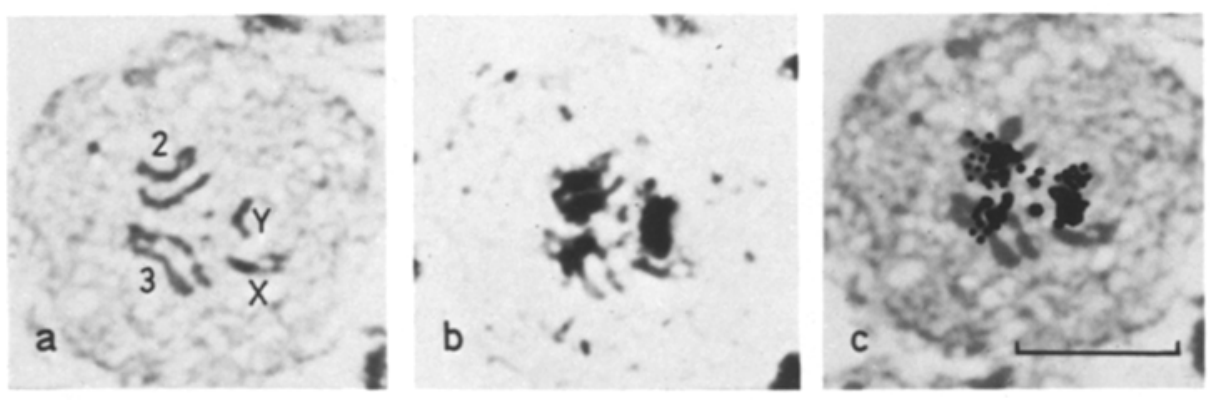

Fig. 2a-c. In situ hybridization of cRNA of XYY $\left(\mathrm{C}_{\mathrm{o}} \mathrm{t} 15\right)$ DNA to somatic chromosomes of the Sw-b stock. a Chromosomes before hybridization. b Autoradiograph of the chromosomes in a after hybridization. c Tracing of the silver grains in b superimposed on the chromosomes of a. Note that the labeling pattern over the $\mathrm{Y}$, second, third and fourth chromosomes is similar to that of Figure 1, but that the $\mathrm{X}$ chromosome has only one grain on the proximal heterochromatic area

large autosomes have silver grains in the centromeric area, with label always heaviest in the vicinity of the centromere of autosome two; (4) autosome four appears to be labeled, with a few silver grains over or very close to this dot-like object. Our conclusions were originally based on the analysis of eighteen cells in which all of the chromosomes were recognizable prior to the hybridization reaction. This labeling pattern has since been confirmed in subsequent experiments on several hundred chromosome complements.

Figure 2 shows the results obtained when the cRNA is transcribed from XYY repeated DNA. In each of nine chromosome preparations the labeling pattern is similar to the above, with but one important exception. In these cells the X chromosome invariably is poorly labeled relative to the other chromosomes. In a number of cases there were no silver grains over the $\mathrm{X}$ at all. To reduce the likelihood that the poor labeling of the $X$ is due to some flaw in the XYY DNA template or some other aspect of the experimental procedure, 
Table 1. Number of silver grains found over all chromosomes of a male complement when hybridized with XY cRNA

\begin{tabular}{lccccc}
\hline Chromosome identification & $Y$ & 2 & 3 & 4 & $X$ \\
\hline $\begin{array}{l}\text { Number of chromosomes } \\
\quad \text { examined in 15 male cells }\end{array}$ & 15 & 30 & 30 & 30 & 15 \\
$\begin{array}{l}\text { Mean and standard error } \\
\quad \text { of number of grains per chromosome } \pm 0.86\end{array}$ & \pm 0.60 & \pm 0.34 & \pm 0.18 & \pm 0.12 \\
\hline
\end{tabular}

we repeated the experiment using cRNA transcribed from a different sample of XYY DNA, this time employing alkali denaturation of chromosomal DNA. The same results were obtained in 20 chromosome preparations.

\section{B. Grain Counts and Specific Labeling Pattern}

\section{Y Chromosome Labeling with $X X$ and $X Y$ cRNA}

To obtain a more precise analysis of the chromosomal distribution of label, we undertook a series of experiments wherein moderate labeling of particularly well-spread male chromosome preparations was sought. Cells to be examined were selected prior to the hybridization solely on the basis of ease of chromosome recognition and lack of overlap. Fifteen male cells hybridized with cRNA from $\mathrm{XX}$ repeated DNA $\left(\mathrm{C}_{0} \mathrm{t} 0.05\right)$ and fifteen male cells hybridized with cRNA from $X Y$ repeated DNA $\left(\mathrm{C}_{0} \mathrm{t} 0.05\right)$ were chosen for this study. Specific activities of the cRNAs were nearly identical $8.6 \times 10^{7} \mathrm{dpm} / \mu \mathrm{g}$ for $\mathrm{XY}$ cRNA and $9.1 \times 10^{7} \mathrm{dpm} / \mu \mathrm{g}$ for XX cRNA. The number of silver grains over each chromosome was counted, with the results tabulated in Tables 1 and 2. Figure 3 is an example of the type of cell used in this analysis.

Based on our previous experiments our prediction was that in cells hybridized with XY cRNA the Y chromosome would be the most heavily labeled, because of the greater amount of heterochromatin in this chromosome. The results for these cells are presented in Table 1.

Student's t-test was used to check for significant differences in the mean number of grains on the $\mathrm{Y}$ chromosome and the rest of the complement. All means, when compared individually to the mean for the $\mathrm{Y}$ chromosome, are significantly different, and, in particular, the apparent difference in mean number of grains on the $\mathrm{Y}$ chromosome and chromosome 2 is significant at $\alpha=0.02$. The statistical significance is upheld whether the $\mathrm{Y}$ chromosome data is compared to all 30 chromosome $2 \mathrm{~s}$, or to a random selection of 15 chromosome $2 s$.

In cells hybridized with $\mathrm{XX}$ cRNA we postulated that the $\mathrm{Y}$ chromosome would again be heavily labeled, but perhaps not as heavily as those hybridized with XY cRNA. This reduction in label would hypothetically be due to the absence of $Y$ chromosome repeated DNA in the original $C_{0} t 0.05$ DNA from which the cRNA was transcribed. The results for cells hybridized with $\mathrm{XX}$ cRNA are presented in Table 2. 

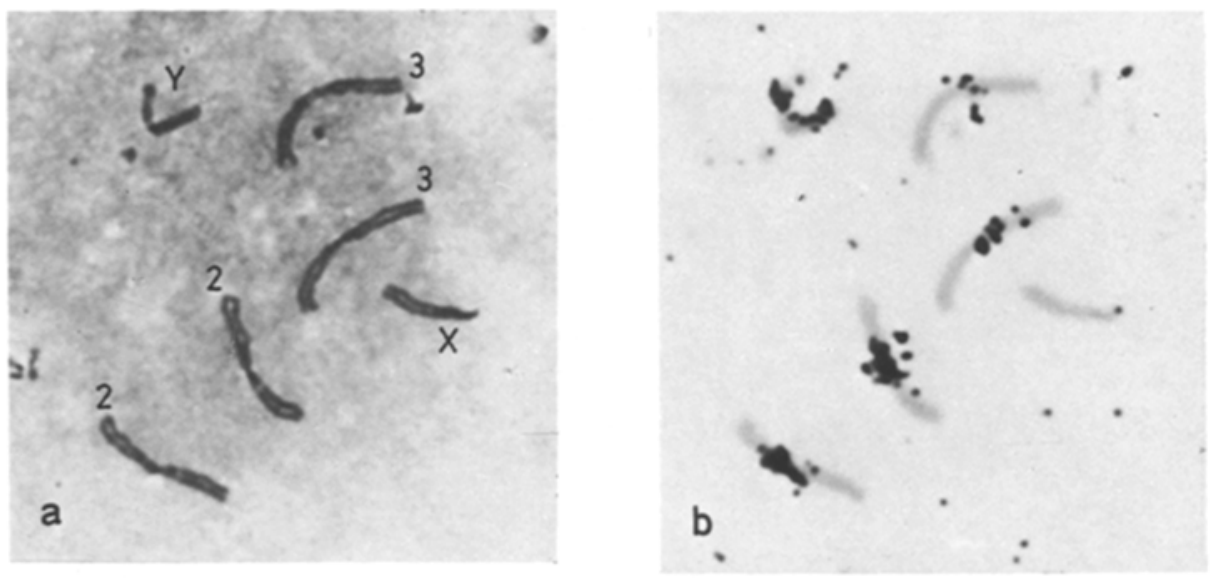

Fig. 3a and b. Chromosomes of a male mitotic complement from $D$. melanogaster. a Chromosomes before hybridization. b Chromosomes after in situ hybridization with XY cRNA derived from $\mathrm{C}_{\mathrm{o}} \mathrm{t}$ 0.05 DNA. Note that the heaviest labeling occurs on the $\mathrm{Y}$ chromosome and that the silver grains are distinct so as to facilitate their quantification

Table 2. Number of silver grains found over all chromosomes of a male complement when hybridized with XX cRNA

\begin{tabular}{llllll}
\hline Chromosome identification & $Y$ & 2 & 3 & 4 & X \\
\hline $\begin{array}{l}\text { Number of chromosomes } \\
\quad \text { examined in 15 male cells }\end{array}$ & 15 & 30 & 30 & 30 & 15 \\
$\begin{array}{l}\text { Mean and standard error } \\
\quad\end{array}$ & 5.27 & 5.97 & 2.17 & 0.37 & 1.87 \\
of number of grains per chromosome & \pm 0.72 & \pm 0.62 & \pm 0.26 & \pm 0.12 & \pm 0.55 \\
\hline
\end{tabular}

Again, the $t$-test was used to check for significant differences between individual means. In contrast to the results obtained with cells hybridized by XY cRNA, the mean number of grains on the $\mathrm{Y}$ chromosome and chromosome 2 are not significantly different even at the level $\alpha=0.5$.

\section{X Chromosome Labeling with XX and XY cRNA}

To augment the observations reported in section $\mathrm{A}$ of Results that the $\mathrm{X}$ chromosome may label less when XYY cRNA is used for hybridization, and more when XX cRNA is used, we examined a large number of chromosome spreads from both male and female cells. Fifty-six X chromosomes from cells hybridized with XX cRNA $\left(\mathrm{C}_{0} \mathrm{t} 0.05\right)$ and $116 \mathrm{X}$ chromosomes from cells hybridized with XY cRNA $\left(\mathrm{C}_{0} \mathrm{t} 0.05\right)$ were examined and the grain counts on each chromosome were recorded (Table 3 ).

A higher percentage of $X$ chromosomes showed no label when incubated with XY cRNA, and a higher percentage of $X$ chromosomes showed relatively 
Table 3. Number of silver grains observed over the $X$ chromosome when hybridized with $X X$ CRNA and XY cRNA

\begin{tabular}{|c|c|c|c|c|c|}
\hline \multirow{2}{*}{$\begin{array}{l}\text { Type of } \\
\text { cRNA }\end{array}$} & \multirow{2}{*}{$\begin{array}{l}\text { Specific } \\
\text { activity }\end{array}$} & \multicolumn{3}{|c|}{ Number of $\mathrm{X}$ chromosomes with } & \multirow{2}{*}{$\begin{array}{l}\text { Total number } \\
\text { of chromosomes } \\
\text { examined }\end{array}$} \\
\hline & & $\begin{array}{l}0 \\
\text { grains }\end{array}$ & $\begin{array}{l}1 \text { to } 3 \\
\text { grains }\end{array}$ & $\begin{array}{l}4 \text { or more } \\
\text { grains }\end{array}$ & \\
\hline $\mathrm{XX}$ & $9.1 \times 10^{7} \mathrm{dpm} / \mu \mathrm{g}$ & $\begin{array}{l}13 \\
(23 \%)^{\mathrm{a}}\end{array}$ & $\begin{array}{l}30 \\
(54 \%)\end{array}$ & $\begin{array}{c}13 \\
(23 \%)\end{array}$ & 56 \\
\hline $\mathrm{XY}$ & $8.6 \times 10^{7} \mathrm{dpm} / \mu \mathrm{g}$ & $\begin{array}{l}36 \\
(31 \%)^{b}\end{array}$ & $\begin{array}{l}74 \\
(64 \%)\end{array}$ & $\begin{array}{l}6 \\
(5 \%)\end{array}$ & 116 \\
\hline
\end{tabular}

a $\%$ chromosomes of 56

b $\%$ chromosomes of 116

heavy label (four or more grains) when incubated with XX cRNA. A $\chi^{2}$ test for independence shows that at the significance level $\mathrm{P}=0.025$, the silver grains are not distributed independently of the type of cRNA used. The largest component of variance occurs when the number of grains observed over the $X$ chromosome is 4 or more.

\section{Discussion}

In this study we find there is an excellent correspondence between the location of repetitious DNA and classically defined regions of constitutive heterochromatin in the somatic chromosomes of $D$. melanogaster. The $\mathrm{Y}$ chromosome shows heavy incorporation of label over its length. The heterochromatic portion of the X chromosome is labeled in every experiment in which cRNA is derived from XX DNA template. (The poor labeling of this chromosome in experiments involving XY or XYY DNA template deserves special consideration and will be discussed below.) The centrometric heterochromatin of both large autosomes was labeled in all experiments. Some portion of autosome four, presumably the pericentric heterochromatin, shows label. These observations are entirely compatible with the concept, fast becoming an axiom in cytogenetics, that highly repetitious and/or satellite DNA is a characteristic property of constitutive heterochromatin.

Keeping in mind the fact that most, if not all, of the silver grains observed in this study derive from cRNA to the most highly repetitious portion of the genome (see Materials and Methods), additional conclusions may be reached. Due to the large number of silver grains over the $Y$ chromosome in all of these experiments, it appears that the $D$. melanogaster $Y$ chromosome contains more highly repetitious DNA than any other chromosome. This finding is in contrast to the apparent lack of repeated DNA in the $Y$ chromosomes of some other Drosophila species, e.g., D. virilis (Gall et al., 1971), and D. hydei (Hennig et al., 1973). The disproportionately heavy labeling of autosome two as compared to autosome three may reflect the presence of more heterochro- 
matin in the centromeric region of the former (Hannah, 1951; Hsu, 1971; Dolfini, 1974). The presence of some highly repetitious DNA in autosome four had previously been inferred on the basis of Giemsa staining (Dolfini, 1974). The $X$ chromosome, at least in experiments involving cRNA to XX DNA, shows label on the proximal third. We conclude, therefore, that there is a reasonably good correlation between the quantity of heterochromatin known to be present in each of these chromosomes and the apparent content of repeated DNA.

We are pleased with the manner in which our experiments merge with and encompass the findings of Sederoff et al. (1975). Their in situ hybridization system used as template only material contained in the $1.705 \mathrm{~g} / \mathrm{cc}$ cryptic satellite. This template, when obtained from an essentially female cell line, nevertheless resulted in substantial hybridization in autosome two and the Y. Our DNA samples which contained all five known D. melanogaster satellites (Peacock et al., 1973, 1977) resulted in label in all regions of heterochromatin. It seems likely that as additional isolated satellites are used in studies of this type, new patterns of shared DNA sequences will emerge. For the present, as a result of the data obtained in the above studies and our observations of the binding of XX derived cRNA, we can only conclude that some of the Y chromosome repeated DNA is homologous to DNA in other chromosomes. Our quantitative results (Tables 1 and 2), however, provide evidence that there is heavier label on the $\mathrm{Y}$ chromosome which has been hybridized, in situ, with cRNA from $X Y$ DNA, than on Y's hybridized with cRNA from XX DNA. We interpret these results as indicating the presence of $\mathrm{Y}$ specific repeated DNA sequences in this species.

We have observed that the $X$ chromosome is poorly labeled by cRNA derived from XYY or XY DNA templates (Fig. 2, Tables 1 and 3) and yet, when the cRNA is obtained from $\mathrm{XX}$ templates, an increased number of silver grains is found over the proximal third of the $X$ (Fig. 1, Tables 2 and 3). While some unknown quirk of our experiments could have caused this, we feel that a reasonable and interesting hypothesis can be offered to explain it. If we assume that some repetitious DNA is absolutely chromosome specific, and if the $\mathrm{X}$ chromosome contains its own brand of this DNA, then the labeling pattern above would result from the experimental design. Repetitious DNA from XX females would of necessity contain a number of X chromosome specific repeated DNA sequences and would result in the heavier labeling pattern seen in Figure 1. Since it has already been established that the Y chromosome contains more highly repetitious DNA than any other chromosome, cRNA from XYY or XY repeated DNA templates would contain, molecule for molecule, less of the hypothetical $X$ chromosome specific cRNA. Under our conditions of hybridization, the lowered probability of correct collisions between the $\mathrm{X}$ chromosome DNA and its specific cRNA complement could very easily account for our data. 


\section{References}

Blumenfeld, M., Forrest, H.S.: Is Drosophila dAT on the Y chromosome? Proc. nat. Acad. Sci. (Wash.) 68, 3145-3149 (1971)

Botchan, M., Kram, R., Schmid, C.W., Hearst, J.E.: Isolation and chromosomal localization of highly repeated DNA sequences in Drosophila melanogaster. Proc. nat. Acad. Sci. (Wash.) 68, 1125-1129 (1971)

Britten, R.J., Kohne, D.E.: Repeated sequences in DNA. Science 161, 529-540 (1968)

Cobel-Geard, S.R., Gay, H.: A new simplified method for the preparation of neuroblast mitotic chromosomes from D. melanogaster. Dros. Inf. Serv. (in press, 1978)

Dolfini, S.F.: The distribution of DNA in the chromosomes of the cultured cells of Drosophila melanogaster. Chromosoma (Berl.) 44, 383-391 (1974)

Gall, J.G., Cohen, E.H., Polan, M.L.: Repetitive DNA sequences in Drosophila. Chromosoma (Berl.) 33, 319-344 (1971)

Hannah, A.: Localization and function of heterochromatin in Drosophila melanogaster. Advanc. Genet. 4, 87-125 (1951)

Hennig, W., Meyer, G.F., Hennig, I., Leoncini, O.: Structure and function of the Y chromosome of Drosophila hydei. Cold Spr. Harb. Symp. quant. Biol. 38, 673-683 (1973)

Hsu, T.C.: Heterochromatin patterns in metaphase chromosomes of Drosophila melanogaster. J. Hered. 62, 285-287 (1971)

Jones, K.W., Robertson, F.W.: Localization of reiterated nucleotide sequences in Drosophila and mouse by in situ hybridization of complementary RNA. Chromosoma (Berl.) 31, $331-345$ (1970)

Laird, C.D.: DNA of Drosophila chromosomes. Ann. Rev. Genet. 7, 177-204 (1973)

Laird, C.D., McCarthy, B.J.: Magnitude of interspecific nucleotide sequence homology within the genome of Drosophila melanogaster. Genetics 60, 303-322 (1968)

Pardue, M.L., Gall, J.G.: Molecular hybridization of radioactive DNA to the DNA of cytological preparations. Proc. nat. Acad. Sci. (Wash.) 64, 600-604 (1969)

Pardue, M.L., Gerbi, S.A., Eckardt, R.A., Gall, J.G.: Cytological localization of DNA complementary to ribosomal RNA in polytene chromosomes of Diptera. Chromosoma (Ber1.) 29, 268-290 (1970)

Peacock, W.J., Brutlag, D., Goldring, E., Appels, R., Hinton, C.W., Lindsley, D.L.: The organization of highly repeated DNA sequences in Drosophila melanogaster chromosomes. Cold Spr. Harb. Symp. quant. Biol. 38, 405-416 (1973)

Peacock, W.J., Appels, R., Dunsmuir, P., Lohe, A.R., Gerlach, W.L.: Highly repeated DNA sequences: Chromosomal localization and evolutionary conservatism. 494-506. In: Int. Cell. Biol. (B.R. Brinkley and K.R. Porter, eds.). New York: Rockefeller University Press 1977

Perreault, W.J., Kaufmann, B.P., Gay, H.: Repeated DNA sequences in the heterochromatic Y chromosome of adult Drosophila melanogaster. Proc. nat. Acad. Sci. (Wash.) 70, 773-777 (1973)

Rae, P.M.M.: Chromosomal distribution of rapidly reannealing DNA in Drosophila melanogaster. Proc. nat. Acad. Sci. (Wash.) 67, 1018-1025 (1970)

Sederoff, R., Lowenstein, L., Birnboim, H.C.: Polypyrimidine segments in Drosophila melanogaster DNA: II. Chromosome location and nucleotide sequence. Cell 5, 183-194 (1975)

Yasmineh, W.G., Yunis, J.J.: Satellite DNA in mouse autosomal heterochromatin. Biochem. biophys. Res. Commun. 35, 779-782 (1969)

Received August 16, 1978 / Accepted September 4, 1978 by H. Bauer

Ready for press September 4, 1978 